\title{
PRODUCTOS DE LA ASIMILACIÓN DEL NITRATO SE DEPOSITAN EN PLANTAS COMO PROTEÍNAS DE ALMACENAMIENTO
}

\section{PRODUCTS OF NITRATE ASSIMILATION ARE DEPOSITED IN PLANTS AS STORAGE PROTEINS}

\author{
Carina C. Cordero ${ }^{1}$, Alfredo Jarma Orozco ${ }^{2}$ \\ Recibido para evaluación: Abril 15 de 2011 - Aceptado para publicación: Junio 14 de 2011
}

\begin{abstract}
RESUMEN
La incorporación del nitrógeno inorgánico en forma de amonio en esqueletos carbonados para la producción de aminoácidos, es uno de los más importantes procesos bioquímicos en los vegetales. Mientras que los productos de la asimilación del CO2 son depositados en las plantas en forma de oligo y polisacáridos, los aminoácidos formados como productos de la asimilación del nitrato son almacenados como proteínas, principalmente de almacenamiento, las cuales no tienen actividad enzimática; son sintetizadas en el retículo endoplasmático rugoso y a menudo depositadas en la célula dentro de órganos proteínicos. De acuerdo con sus propiedades de solubilidad, las proteinas pueden ser albúminas (solubles en agua pura), globulinas (solubles en soluciones salinas diluidas), glutelinas (solubles en soluciones diluidas alcalinas y acidas) y prolaminas (solubles en etanol acuoso). No obstante, cuando las estructuras de las proteínas se determinaron, resultó que las glutelinas y prolaminas estaban estrechamente relacionadas de manera estructural. En términos generales, estas proteínas, además de tener función de almacenamiento, protegen a las semillas de insectos plagas y patógenos, y son completamente degradadas por proteinasas y peptidasas en la vacuola, donde los aminoácidos liberados son proporcionados como material de construcción para la germinación de la planta. Con esta revisión se proyecta reconocer las principales proteínas de almacenamiento y su función en diferentes especies vegetales en las cuales están depositadas, resaltando que las globulinas son las más abundantes en la naturaleza.
\end{abstract}

Palabras clave: nitrógeno, albúminas, globulinas, prolaminas, proteinasas.

${ }^{1}$ Candidata Maestría Ciencias Agronómicas - Universidad de Córdoba, Montería, Colombia. Cel. 3116737732. carynace@ hotmail.com

²Ph.D. Fisiología de Cultivos. Facultad Ciencias Agrícolas - Universidad de Córdoba, Montería - Colombia. ajarma@ correo.unicordoba.edu.co 


\section{SUMMARY}

Assimilation of inorganic nitrogen in ammonium form, in carbon skeletons, for amino acid production, is one of the most important biochemical processes in plants. While the products of $\mathrm{CO} 2$ assimilation are deposited in oligo and polysaccharides form in plants, amino acids formed as products of nitrate assimilation are stored as proteins. These are mainly storage proteins, which have not enzymatic activity, are synthesized in the rough endoplasmic reticulum and often are deposited in the cell within protein bodies. According to their solubility properties, proteins can be albumins (soluble in pure water), globulins (soluble in diluted salt solutions), glutelins (soluble in alkali and acid diluted solutions) and prolamins (soluble in aqueous ethanol). However, when the protein structures were determined, glutelins and prolamins were closely related. Therefore, glutelins are considered members of the prolamins. Overall, these proteins, also have storage function in different plant species where are deposited, protect seeds from attack by insect pests and pathogens, and are completely degraded by proteinases and peptidases in the vacuole, where the released amino acids are provided as a construction material for plant germination. This review is planned to recognize the major storage proteins and their role in different plant species in which they are presented, emphasizing that the globulins are the most abundant in nature.

Key words: nitrogen, albumin, globulin, prolamin, proteinases.

\section{INTRODUCCIÓN}

A nivel mundial, aproximadamente el $70 \%$ de la demanda humana de proteína se centra en el consumo de semillas, ya sea directa o indirectamente por la alimentación a los animales o la producción de carne. Sin embargo, en muchas proteínas de almacenamiento vegetales (PA), el contenido de ciertos aminoácidos esenciales para la nutrición de personas y animales es muy bajo. En cereales, las PA son deficientes en treonina, triptófano y particularmente lisina, mientras que en las leguminosas hay una deficiencia de metionina (Heldt y Heldt 2005). No obstante, todas las PA cumplen funciones especificas en cada uno de los cultivares donde se encuentran, y en consecuencia son productos de la asimilación del nitrato en las plantas.

En una planta en crecimiento activo, el $\mathrm{N}$ es tomado como nitrato $y$, en menor medida como amoníaco. El nitrato es reducido en el citoplasma por el nitrato reductasa, y el nitrito entra a los cloroplastos donde se reduce aún más antes de la incorporación en aminoácidos. Además de este flujo constante de $\mathrm{N}$, hay reciclaje de compuestos nitrogenados, que también producen el amoníaco que se necesita para ser asimilado. Este reciclaje resulta de la operación del ciclo fotorespiratorio con la oxidación de la glicina (Gly) en la mitocondria, de la degradación de las PA en semillas, hojas y tejidos de la corteza, y de la degradación de proteínas y ácidos nucleicos que están relacionadas con la senescencia celular y fenómenos apoptóticos (Lancien et al. 2000). Por esto, y considerando la importancia del nitrógeno en el metabolismo de las plantas, es un objetivo fundamental de la ingeniería genética, mejorar la composición de aminoácidos de las PA de los productos de la cosecha, que a su vez son productos de la asimilación de este nutriente.

En consecuencia a lo anterior, la presente revisión pretende mostrar aspectos importantes de las principales proteínas de reserva desde 
su síntesis, almacenamiento y degradación, además de las características y funciones de estas en las diversas especies donde son encontradas, ya sea como PA y/o como mecanismos de defensa de la planta ante el ataque de insectos, plagas y patógenos.

\section{Clasificación de las Proteínas de almacenamiento (PA)}

Osborne (1924), clasificó las proteínas vegetales de acuerdo con sus propiedades de solubilidad; fraccionó las proteínas vegetales en albúminas (solubles en agua pura), globulinas (solubles en soluciones salinas diluidas), glutelinas (solubles en soluciones diluidas alcalinas y acidas) y prolaminas (solubles en etanol acuoso). Sin embargo, cuando las estructuras de las proteínas se determinaron posteriormente, resultó que glutelinas y prolaminas estaban estrechamente relacionadas de manera estructural, por lo que, en la literatura más reciente, las glutelinas son consideradas como miembros del grupo de las prolaminas. Para el caso de las globulinas, estas son depositadas en las vacuolas de almacenamiento de proteína (VAP); por su parte, las prolaminas se acumulan en organelos proteínicos derivados del retículo endoplasmático RE que son formados en el lúmen del RE rugoso (Kawakatsu et al. 2010).

La síntesis de las PA depende del nitrógeno disponible en la semilla, el cual puede ser controlado por la importación de aminoácidos a través de transportadores específicos (Rolletschek et al. 2005). Mientras que los productos de la asimilación del $\mathrm{CO}_{2}$ son depositados en las plantas en forma de oligo y polisacáridos, los aminoácidos formados como productos de la asimilación del nitrato son almacenados como proteínas. Estas son principalmentePA, lascuales notienen actividad enzimática y son a menudo depositadas en la célula dentro de órganos proteínicos, rodeados por una sola membrana y que se derivan del sistema de endomembranas del (RE) y del aparato de Golgi o las vacuolas. En tubérculos de papa por ejemplo, las PA son almacenadas en estas últimas (Heldt y Heldt 2005).

Las VAP son compartimentos especiales en donde se acumulan las PA de las semillas (Olbrich et al. 2007). El estudio de la vía de transporte por este compartimento es muy importante no sólo por el papel de las PA en la nutrición de humanos y animales, sino también por la posibilidad de acumularse en este compartimento y recombinar proteínas para aplicaciones terapéuticas (Jiang et al. 2001; Molina et al. 2006). La vía de transporte hacia la VAP ha sido bien caracterizada en guisante y zapallo (Molina et al. 2006).

Las PA pueden ser depositadas en varios órganos de la planta (Heldt y Heldt 2005). La mayoría del $\mathrm{N}$ en árboles caducifolios de zonas templadas en invierno, se almacena como una PA especializada denominada proteína de almacenamiento de la corteza (PAC). Conjuntamente, esta PAC se acumula en la corteza interior de aquellas plantas expuestas a fotoperíodos de día corto o niveles elevados de nitrógeno (Zhu y Coleman, 2001).

Por otra parte, se ha reportado la existencia de una proteína relacionada con quitinasa, que se comporta como una PA vegetal específica de frutas y que se acumula durante la formación temprana del fruto, sirviendo como fuente de aminoácidos para la síntesis de proteínas 
asociadas con la maduración (Peumans et al. 2002).

En términos generales, para el caso de cereales y leguminosas, las PA pueden estar localizadas en el endospermo de semillas de las primeras y en los cotiledones de la mayoría de semillas de estas últimas. Es importante considerar que en los cereales las cantidades del contenido de proteína son del $10 \%$ a $15 \%$ del peso seco, en algunas leguminosas (por ejemplo la soya) es más alta (del $40 \%$ al 50\%), y que cerca del 85\% de estas proteínas, son PA (Heldt y Heldt 2005).

En la actualidad, existen muchos trabajos sobre la presencia y funcionalidad de las diferentes PA vegetales. Ramos (2009), realizó la detección de lunasina (péptido descubierto en PA de la soya) en extractos proteínicos totales así como en las fracciones solubles de semillas de lupinos; Torres et al. (2001), realizaron una investigación sobre la distribución subcelular de reticuloplasminas nativas $y$ artificiales en el endospermo, callos y tejidos de la hoja de arroz transgénico (Oryza sativa). De igual forma en arroz, las PA de las semillas también pueden ser sintetizadas $y$ depositadas en organelos de almacenamiento en el endospermo durante la maduración de la semilla como fuente de nitrógeno para la germinación de plántulas (Kawakatsu et al. 2010).

Es imporante recordar que las enzimas proteolíticas (proteasas) son agrupadas en proteinasas y peptidasas, siendo las proteinasas, las que catalizan la degradación de la proteína en fracciones de péptidos pequeños y las peptidasas, las que hidrolizan enlaces peptídicos específicos o rompen completamente péptidos a aminoácidos (Colin 2009). La relación de este tipo de enzimas con el conocimiento existente sobre la movilización de los aminoácidos desde las PA, se deriva principalmente de las investigaciones de los procesos durante la germinación de semillas. En la mayoría de los casos, la germinación que es inducida por la absorción de agua, hace los cuerpos proteínicos para formar una vacuola. Consecuentemente, la hidrólisis de las PA es catalizada por proteinasas, que están en parte depositadas como proformas inactivas junto con las PA en los cuerpos proteínicos; por otra parte, otras proteinasas son sintetizadas de nuevo y transferidas a través del lumen del RE y del aparato de Golgi a las vacuolas (Müntz et al. 2001).

Colin 2009, indica que la actividad proteolítica de la harina de trigo y centeno, es atribuida principalmente a proteinasas aspárticas como lo identifica (Rocha et al. 2010) y carboxipeptidadas, y que ambos grupos de proteasas son activas bajo condiciones acidas. Las proteinasas son sintetizadas inicialmente como proformas inactivas y la activación de estas pro-proteinasas procede por proteólisis limitada, en la cual, una sección de la secuencia es removida por una peptidasa específica. El resto del polipéptido representa la proteinasa activa. La degradación de las PA es entonces iniciada por esta proteólisis limitada, donde una proteinasa específica primero remueve pequeñas secciones de la secuencia de la proteína, lo que resulta en un cambio en la conformación de la PA. Posteriormente, la proteína desdoblada es entonces susceptible a la hidrólisis por varias proteinasas como exopeptidasas, las cuales separan unos aminoácidos, y después los otros, 
del final de la molécula de proteína, y las endopeptidasas, las cuales actúan dentro de la molécula (Müntz 2007).

A continuación se hace una breve discución de cada uno de los grupos de PA de acuerdo a sus propiedades de solubilidad: albúminas, globulinas y pro laminas. Al final se mencionan aspectos de algunas propiedades de las proteínas $2 \mathrm{~S}$ y de la función de defensa de algunas PA. Mientras que las globulinas comprenden PA, las albúminas forman una clase heterogénea de proteínas independientes que incluyen proteínas metabólicas de las sustancias almacenadas en la semilla (glicosidasas), estructurales o reguladoras y proteolíticas como las proteasas, que juegan un papel importante en la degradación proteínica durante la germinación. Adicionalmente, muchas albúminas solubles en agua también se han clasificado como proteínas de reserva (Pereira et al. 2000), principalmente, las albúminas tipo $2 \mathrm{~S}$ a las cuales se les ha atribuido este papel, además de proveer azufre durante la germinación. En semillas de leguminosas, estas son fuente de lisina y metionina y reguladoras en el metabolismo de poliaminas (Gaur et al. 2010; Peralta 2004).

\section{Globulinas}

Las globulinas de almacenamiento se producen en cantidades variables en casi todas las plantas (Thompson et al. 2009), y contienen grandes cantidades de acido glutámico, acido aspártico, leucina, aminoácidos básicos y amidas (Peralta 2004; Herman y Larkins 1999; Scott 2008).

Las globulinas más importantes pertenecen a los grupos legumina (globulina con coeficiente de sedimentación 11S) y vicilina (globulina con coeficiente de sedimentación 7S). Ambos están codificados por una familia multigénica y a su vez, estas familias descienden de un ancestro común (Thompson et al. 2009). Las familias de genes de legumina y vicilina han sido objeto para diversificar la selección que ha dado lugar a una amplia gama de adaptaciones estructurales y funcionales, lo que permite una mayor variedad entre las plantas con semilla (Scott 2008). Adicionalmente, dentro del grupo de las globulinas también se ha identificado otra proteína denominada patatina, la cual es la principal PA en los tubérculos (Heldt y Heldt 2005).

Globulina $11 S$ o Legumina. Es la principal PA de semillas de leguminosas. En el caso del Haba (V. faba), el 75\% de las PA totales tiene como componente este tipo de globulina (Thompson et al. 2009). Es un hexámero con masa molecular de 300 a 400 kDa. Los monómeros contienen dos diferentes cadenas peptídicas ( $\alpha$ y $\beta$ ) que están unidas por un puente disulfuro. La cadena $\alpha$-larga, usualmente tiene masa molecular de aproximadamente 35 a 40 $k D a$, y la cadena $\beta$-pequeña tiene una masa molecular de $20 \mathrm{kDa}$. Los hexámeros pueden estar compuestos de diferentes monómeros ( $\alpha$ y $\beta$ ). Algunos contienen metionina mientras que otros no. En el hexámero, las moléculas de proteína están organizadas en un paquete muy regular y pueden ser depositados en esta forma en los órganos proteínicos.

Globulina 7S o Vicilina. Estas son estructuras triméricas que consisten de subunidades de aproximadamente $50 \mathrm{kDa}$, y muestra similitudes en su secuencia de aminoácidos con la legumina, pero se produce principalmente 
como un trímero, del cual los monómeros se componen de solamente una cadena peptídica. Debido a la falta de cisteína, los monómeros de vicilina son incapaces de formar puentes disulfuro. En contraste con las leguminas, las vicilinas están a menudo glicosiladas y contienen residuos de carbohidratos, tales como manosa, glucosa y $\mathrm{N}$-acetilglucosamina. También se han reportado proteínas homólogas a las vicilinas, que en la actualidad se conocen como convicilinas, cuya masa molecular es de aproximadamente 70 kDa (Dam et al. 2009).

Existen estudios en diversas especies vegetales sobre la identificación y caracterización de las globulinas. En frijol común, las principales PA de semillas son la phaseolina (vicilina) y la fitohemaglutinina (Pereira et al. 2000; Park et al. 2004). En cacao son proteínas vacuolares de reserva que representan el $43 \%$ de las proteínas de la semilla (Ortiz et al. 2006; Buyukpamukcu et al. 2001). En Jatropha curcas, las fracciones principales de proteinas de reserva corresponden a globulinas (representan el $42,2 \%$ de las proteinas presentes en la semilla) como las mas predominantes, seguidas de las glutelinas $(32,6 \%)$, albúminas $(15,1-11,8 \%)$ y prolaminas (6,4-3,6\%) (Peralta 2004). En el grano de trigo, la capa interna contiene proteínas implicadas en el metabolismo y enzimas de defensa e inhibidores como la globulina 7S (específica para esta capa) (Jerkovic et al. 2010).

Patatina. Es el tercer tipo de globulina reportado y se considera una glicoproteína. En minituberculos frescos de papa (Solanum tuberosum L.) se logró identificar este polipéptido de 40 a 45 kDa, y su abundancia relativa puede representar hasta el $50 \%$ de la proteína total de estos. En los estadíos de desarrollo de las partes de los órganos de la planta de papa, se expresa esta PA, que se considera un marcador de la inducción y desarrollo de dichos tubérculos (Coria et al. 2004).

\section{Prolaminas}

Las prolaminas se encuentran mayoritariamente en semillas de cereales. Están presentes como una mezcla polimórfica de muchas diferentes subunidades de 30 a 90 kDa cada una. Algunas de estas subunidades contienen residuos de cisteína y están unidos por puentes disulfuro (Zerené et al. 2000). Otra característica relevante de estas PA es que son ricas en prolina y glutamina y generalmente deficientes en aminoácidos esenciales como la lisina y el triptófano (Sabelli y Larkins 2009).

De acuerdo al cereal de procedencia, las prolaminas reciben distintos nombres: trigo (gliadina), avena (avenina), cebada (hordeína) y centeno (secalina) entre otros. La gliadina es las más utilizada a nivel industrial y constituye el mayor problema, ya que en muchos alimentos la harina de trigo está presente como ingrediente principal o como aditivo y en otros, está presente por posibles contaminaciones cruzadas que pueden darse a nivel industrial o en la comercialización de los alimentos (López et al. 2010).

En los géneros Hordeum (cevada), Pennisetum (millo), Secale (centeno), Sorghum (sorgo), Triticum (trigo) y Zea (maiz), las prolaminas representan del 50 al $60 \%$ de las proteinas totales del endospermo, por el contrario en Arroz y Avena, representan sólo del 5\% al 10\%, (Sabelli y Larkins 2009); y según 
reportes de su sitio de acumulación, en el endospermo del arroz (O. sativa) y el trigo (Triticum aestivum), parecen acumularse en los organelos proteínicos derivados del RE (Chrispeels y Herman 2000).

Las prolaminas pueden ser gluteninas, gliadinas y zeinas.

Gluteninas. Las moléculas de glutenina difieren en tamaño. Estas proteínas, son moléculas grandes que forman polímeros heterogéneos constituidos por varias subunidades, que están unidas por puentes disulfuro. Las gluteninas se separan en dos grupos distintos en base al tamaño de los polipéptidos que forman sus polímeros; las subunidades de bajo peso molecular (BPM) y las de alto peso molecular (APM). El peso molecular de estas últimas oscila entre 100 y varios millones de kDa (Zerené et al. 2000; Gianibelli et al. 2001; Wieser 2007; Díaz et al. 2006). A pesar de que las subunidades de APM son similares en su estructura, la subunidad 5 tiene un residuo de cisteína adicional, lo que puede estar relacionado con su mayor peso (Díaz et al. 2006).

Las gluteninas de APM son identificadas de acuerdo a su movilidad electroforética en geles de poliacrilamida en presencia de dodecil sulfato de sodio, incluyendo el genoma del cual se deriva la subunidad y además el número cromosómico (Gianibelli et al. 2001). En un trabajo realizado con trigos mexicanos, en el cual se determinó la influencia de subunidades de estas prolaminas de APM en 69 líneas de dicho material vegetal, se concluyó que las propiedades de panificación como volumen de pan, textura de la miga y contenido de proteina, son influenciadas diferencialmente por los alelos de gluteninas de APM presentes en estos trigos (Olán et al. 2006).

Gliadinas. Son prolaminas con alto nivel de prolina (15-30\%) y glutamina (35-45\%) y bajo contenido de lisina $(0,2-0,9 \%)$. Son un grupo amplio de proteínas, con propiedades similares pero muy heterogéneas en tamaño y punto isoeléctrico. Su peso molecular medio es de $40 \mathrm{kDa}$, presentan cadena simple y son extremadamente adhesivas cuando están hidratadas (Zerené et al. 2000). Se encuentran principalmente como polipéptidos monoméricos, es decir proteinas con una sola cadena polipetídica y pueden ser clasificadas de acuerdo a sus estructuras primarias en gliadinas $\alpha, \beta, \gamma$ y $\omega$. Las cadenas de disulfuro pueden estar ausentes o presentes como cadenas cruzadas y son parcialmente responsables de las propiedades reológicas de la masa para la fabricación de pan en la que se encuentren (Wieser 2007).

Las gliadinas tienen poca o nula resistencia a la extensión y parecen ser las responsables de la cohesividad de la masa. El análisis de estas prolaminas, separadas en un gel de electroforesis de dos dimensiones sugiere que cada variedad contiene aproximadamente 45 polipéptidos diferentes (Zerené et al. 2000; Wieser 2007; Colin 2009; Sabelli y Larkins 2009; Martínez et al. 2007).

El peso molecular del gluten detrigoseencuentra en un rango de 30.000 a más de 10 millones de daltons. Sus proteinas originales gliadina y glutenina se presentan aproximadamente en proporciones iguales y ambas constituyen del 80 al $85 \%$ de las proteinas totales de esta 
especie vegetal. Estos tipos de proteinas se distinguen por su solubilidad en agua-alcohol (60\% de alcohol), donde las gliadinas son solubles y las gluteninas insolubles (Martínez et al. 2007; Colin 2009; Espitia et al. 2008; Jobet y Hewstone 2003). Algunas características genéticas y de peso molecular de estas PA son revisadas en Kawaura et al. (2005), Kawakatsu et al. (2010) y Yamakawa et al. (2007).

Finalmente, las prolaminas del trigo, centeno y avena entre otros cereales, contienen estructuras que son dañinas para la gente que es sensible al gluten, por lo que la degradación de estas durante el procesamiento del alimento puede eliminar este problema (Colin 2009). Conjuntamente, Loponen et al. (2007), en un estudio que evaluaron la hidrólisis de las prolaminas durante la fermentación de masas agrias de trigo fermentado, encontraron que todas las prolaminas de trigo (gliadinas y gluteninas) fueron degradas durante la fermentación.

Zeinas. También pertenecen a la familia de las prolaminas (Chrispeels y Herman 2000), y son las principales PA del maíz, las cuales progresivamente se acumulan durante el desarrollo del endospermo (Mechin et al. 2007). Existen diferentes tipos de zeinas bien conocidas: $\delta$ zeina, la a zeina de $22 \mathrm{kDa}$, la $\beta$ zeina, y la $\gamma$ zeina de interferencia de ARN; a zeina ha sido una de las mas estudiadas en los fenotipos opacos o no vítreos de maíz, está relacionada con la arquitectura de las semillas y por ende ligada al lugar que controla la acumulación y adecuada deposición de zeinas, en organelos especializados del endospermo conocidos como cuerpos proteínicos (Cossegal et al. 2008; Wu y Messing 2010). De hecho, una cantidad suficiente de las zeinas de $22 \mathrm{kDa}$ es necesaria para el mantenimiento normal de la forma de estos (Wu y Messing 2010). Tambien en maíz se encontró, que el tamaño, el número y la estructura de dichos cuerpos proteínicos de zeína influyen en la textura de endospermos maduros, y que además, los niveles de oxígeno en parte, pueden interactuar con los aminoácidos y la síntesis de proteínas, ya que están más concentrados en las células externas del endospermo como la aleurona, donde el oxígeno está más disponible (Bethke et al.1998; Chung et al. 2007; Gavazzi et al. 2007; Chrispeels y Herman 2000).

\section{Las proteínas 2s están presentes en las semillas de plantas dicotiledóneas}

Las proteinas $2 \mathrm{~S}$ son también PA ampliamente distribuidas. Estas representan un grupo heterogéneo de proteinas de las cuales la única definición es su coeficiente de sedimentación de cerca de 2 svedberg (S). Las investigaciones acerca de su estructura, han revelado que la mayoría de proteínas $2 \mathrm{~S}$ tienen una estructura interrelacionada y son posiblemente derivadas junto con las prolaminas, de una proteína ancestro común. Napina, la PA predominante en la colza, es un ejemplo de este tipo de proteínas, y tiene una importancia económica considerable, ya que, después de que el aceite se ha extraído, el resto de la colza es utilizado como forraje. Napina y otras proteínas $2 \mathrm{~S}$ relacionadas, constan de 2 cadenas de polipéptidos relativamente pequeñas de 9 y 12 kDa, las cuales están unidas por puentes disulfuro. Cabe mencionar que actualmente, poco se sabe sobre la aglomeración de proteínas-2S en los organelos proteínicos (Heldt y Heldt 2005). 


\section{Proteínas especiales protegen a las semillas de ser consumidas por los animales}

Las proteinas de algunas semillas depositadas en sus organelos proteínicos, además de actuar como PA, las protegen de ser consumidas (Zhu-Salzman et al. 2008; Liu et al. 2005). Por ejemplo la vicilina, tiene una función de defensa mediante la unión a la matriz de la quitina de los hongos e insectos (Sales et al. 1992); en algunos insectos ésta interfiere con el desarrollo de las larvas, así como las leguminas (Pereira et al. 2000). Asimismo, las semillas de algunas leguminosas contienen lectinas, que se unen a los residuos de azúcar, independientemente de si se trata de azúcares libres o componentes de glicolípidos o glicoproteínas (Hernández et al. 2005). A menudo presentan actividad anti-insecto (ZhuSalzman et al. 2008); cuando estas semillas son consumidas por los animales, las lectinas se unen a las glicoproteínas en el intestino y por lo tanto, interfieren con la absorción de nutrientes.

Las semillas de algunas leguminosas y otras plantas también contienen inhibidores de las proteinasas, los cuales bloquean la digestión de las proteínas inhibiendo proteinasas en el tracto digestivo de los animales (Ferreira y Correa 2004; Heldt y Heldt 2005). Debido a su contenido de lectinas e inhibidores de la proteinasa, muchos frijoles y otros productos vegetales son aptos para el consumo humano solamente después de la desnaturalización por la cocción. Esta es la razón del porqué los humanos han aprendido a cocinar (Ferreira y Correa 2004). Conjuntamente, en fríjol también se han encontrado inhibidores de la amilasa, los cuales específicamente inhiben la hidrólisis del almidón por las amilasas en el tracto digestivo de ciertos insectos (Heldt y Heldt 2005).

\section{CONCLUSIONES}

Los aminoácidos formados como productos de la asimilación del nitrato en las plantas, son almacenados como proteinas, que se sintetizan en el RE rugoso y se depositan en organelos ocuerposproteínicos.

Algunas de las principales PA son las albúminas, globulinas, prolaminas y proteinas 2S, siendo albúminas y globulinas, las principales proteínas de semillas de muchas leguminosas, y las prolaminas, las proteinas con mayor abundancia en los cereales. La importancia de las anteriores, radica en que además de actuar como PA, constituyen mecanismos de defensa en la planta ante el ataque de insectos plagas y patógenos. De hecho en actualidad, con el uso de la proteómica y técnicas de ingeniería genética, se ha tratado de proteger a las semillas de gran diversidad de especies contra las pérdidas causadas por éstos.

Finalmente, las proteínas de la semilla también incluyen hidrolasas como amilasas, proteinasas y lipasas que actúan en la movilización de los diversos tipos de compuestos de reserva asociados, cuyos productos se utilizarán durante la germinación para la síntesis de nuevos tejidos. 


\section{REFERENCIAS}

Bethke, P., Swanson, S., Hillmer, S. y Jones, R. 1998. From Storage Compartment to Lytic Organelle: The Metamorphosis of the Aleurone Protein Storage Vacuole. Plant Physiology. 82: 399-412.

Buyukpamukcu, E., Goodall, D., Hansen, C., Keely, B., Kochhar, S. y Wille, H. 2001. Characterization of peptides formed during fermentation of cocoa bean. J. Agric. Food Chem. 49 (12): 5822-5827.

Chrispeels, M.J. y Herman, E. M. 2000. Endoplasmic Reticulum-Derived Compartments Function in Storage and as Mediators of Vacuolar Remodeling via a New Type of Organelle, Precursor Protease Vesicles. Plant Physiology. 123 (4):1227-1234.

Chung, T., Kim, C., Nguyen, H. N., Meeley, R. B. y Larkins, B. A. 2007. The Maize Zmsmu2 Gene Encodes a Putative RNA-Splicing Factor That Affects Protein Synthesis and RNA Processing during Endosperm Development. Plant Physiology. 144 (2):821-835.

Colin, J. 2009. Composición del inóculo (Lb. plantarum, Lb, brevis y Lb. sanfranciscensis) y su efecto en las propiedades viscoelasticas de las masas agrias. Tesis de grado de Maestría. Instituto politécnico nacional CICATAIPN. Mexico D.F. Pag 59.
Coria, N.A., Perez, A., Sarquís, J.I., Cantú, I., Gonzalez, H. y Gómez, M.V. 2004. Regeneración de la planta de papa (Solanum tuberosum I) in vitro a partir del estolón. Ciencia UANL. VII (003): 361-370.

Cossegal, M., Chambrier, P., Mbelo, S., Balzergue, S., Martin-Magniette, M.L., Moing,A., Deborde, C., Guyon, V., Perez, P. y Rogowsky, P. 2008. Transcriptional and Metabolic Adjustments in ADPGlucose Pyrophosphorylase-Deficient bt2 Maize Kernels. Plant Physiology. 146 (4): 1553-1570.

Dam, S., Laursen, B. S., Ørnfelt, J.H., Jochimsen, B., Stærfeldt, H.H., Friis, C., Nielsen, K., Goffard, N., Besenbacher, S., Krusell, L., Sato, S., Tabata, S., Thøgersen, I.B., Enghild, J. J., y Stougaard, J. 2009. The Proteome of Seed Development in the Model Legume Lotus japonicus. Plant Physiology. 149 (3):1325-1340.

Díaz, P., Dalla, M., Vázquez, D. y Castro, M. 2006. Elementos de Análisis Cualitativo y Cuantitativo en Proteínas del Gluten de Trigo. Agricultura Técnica. 66 (4):360-369.

Espitia, E., Martínez, E., Peña, R.J., Villaseñor, H. E., Huerta, J. 2008. Polimosrfismo de gluteninas de alto peso molecular y su relación con trigos harineros para temporal. Agricultura técnica en México. 34(001): 57-67.

Ferreira, M. y Correa, E. M. 2004. Recognition of n-acetylglucosamine (GlyNac) and poly-n-acetyllactosamine residues in 
vessels of the rat pineal gland. Int. J. Morphol. 22 (4).

Gaur, V., Qureshi, I. A., Singh, A., Chanana, V. y Salunke, D. M. 2010. Crystal Structure and Functional Insights of Hemopexin Fold Protein from Grass Pea. Plant Physiology. 152 (4):1842-1850.

Gavazzi, F., Lazzari, B., Ciceri, P., Gianazza, E. y Viotti, A. 2007. Wild-Type Opaque and Defective opaque Polypeptides Form Complexes in Maize Endosperm Cells and Bind the Opaque2-Zein Target Site. Plant Physiology. 145 (3):933-945.

Gianibelli, M.C., Larroque, O.R., Macritchie, F. and Wrigley, C.W. 2001. Biochemical, genetic, and molecular characterization of wheat endosperm proteins. AACC, Inc. Disponible en http://www.aaccnet.org/ cerealchemistry/freearticle/gianibelli. pdf. [1 Septiembre 2010].

Heldt, H. y Heldt F. 2005. Plant Biochemistry. Hans. 2005 Editorial Coordinator Kelly Sonnack. p 353-360.

Herman, E. y Larkins, B. 1999. Protein Storage Bodies and Vacuoles Climate Stress Laboratory. The Plant Cell. 11 (4): 601614.

Hernández, P., Perez, E., Martínez, L., Ortiz, B. y Martínez, G. 2005. Las lectinas vegetales como modelo de estudio de las interacciones proteina carbohidrato. Revista de educación bioquimica. 24 (001):21-27 .
Jerkovic, A., Kriegel, A. M., Bradner, J.R., Atwell, B. J., Roberts, T.H. y Willows, R.D. 2010. Strategic Distribution of Protective Proteins within Bran Layers of Wheat Protects the Nutrient-Rich Endosperm. Plant Physiology. 152 (3):1459-1470.

Jiang, L., Phillips, T., Hamm, C., Drozdowicz, Y., Rea, P., Maeshima, M., Rogers, S. y Rogers, J. 2001. The protein storage vacuole: a unique compound organelle. The Journal of Cell Biology. 155 (6):9911002.

Jobet, C. y Hewstone, C. 2003. Kumpa-inia: nueva variedad de trigo invernal para el sur de Chile. Agricultura Técnica. 63(1): 81-86.

Kawakatsu, T., Hirose, S., Yasuda, H. y Takaiwa, F. 2010. Reducing Rice Seed Storage Protein Accumulation Leads to Changes in Nutrient Quality and Storage Organelle Formation. Plant Physiology. 154 (4):1842-1854.

Kawaura, K., Mochida, K. y Ogihara, Y. 2005. Expression Profile of Two StorageProtein Gene Families in Hexaploid Wheat Revealed by Large-Scale Analysis of Expressed Sequence Tags. Plant Physiology. 139 (4):1870-1880.

Lancien, M., Gadal, P. y Hodges, M. 2000. Enzyme Redundancy and the Importance of 2-Oxoglutarate in Higher Plant Ammonium Assimilation. Plant Physiology. 123 (3):817-824. 
Liu, Y., Ahn, J., Datta, S., Salzman, R.A., Moon, J., Huyghues-Despointes, B., Pittendrigh, B., Murdock, L.L., Koiwa, H. y Zhu-Salzman, K. 2005. Arabidopsis Vegetative Storage Protein Is an Anti-Insect Acid Phosphatase. Plant Physiology. 139: 1545-1556.

López, B.L., Marcelo, L., Vidueiros, S.M., Pallaro, A., Valencia, M.E. 2010. Determinación del contenido de gliadinas en alimentos elaborados con amaranto, quínoa y/o chía. Revista Chilena de Nutrición. 37(1):80-86.

Loponen, J., Sontag-Strohm, T., Venalainen, J. y Salovaara, H. 2007. Prolamin hydrolysis in wheat sourdoughs with differing proteolytic activities. Journal of Agricultural and Food Chemistry. 55 (3):978-984.

Martínez, E., Espitia, E., Benítez, I., Peña, R. J., Santacruz, A. y Villaseñor, H. E. 2007. El complejo Gli-1/Glu-3 y las propiedades reológicas y volumen de pan de trigos harineros. Revista Fitotecnia Mexicana. 30(002):167-172.

Mechin, V., Thevenot, C., Guilloux, M.L., Prioul, J.L. y Damerval, C. 2007. Developmental Analysis of Maize Endosperm Proteome Suggests a Pivotal Role for Pyruvate Orthophosphate Dikinase. Plant Physiology. 143 (3):1203-1219.

Molina, M.I., Otegui, M. y Petruccelli, S. 2006. Sunflower storage proteins are transported in dense vesicles that contain proteins homologous to the pumpkin vacuolar sorting receptor 72 . Electronic Journal of Biotechnology. 9 (3):326-330.

Müntz, K., Belozersky, M., Dunaevsky, Y., Schlereth, A. y Tiedemann, J. 2001. Stored proteinases and the initiation of storage protein mobilization in seeds during germination and seedling growth. Journal of Experimental Botany. 52 (362): 1741-1752.

Müntz, K. 2007. Protein dynamics and proteolysis in plant vacuoles. Journal of Experimental Botany. 58 (10):2391-2407.

Olán, M., Espitia, E., Molina, J. D., Peña, R. J., SantaCruz, A. y Villaseñor, H. E. 2006. Efecto de diferentes subunidades de gluteninas APM sobre la calidad panadera en trigos harineros mexicanos. Revista fitotecnia mexicana. 29 (004): 291-297.

Olbrich, A., Hillmer, S., Hinz, G., Oliviusson, P. y Robinson, D. G. 2007. Newly Formed Vacuoles in Root Meristems of Barley and Pea Seedlings Have Characteristics of Both Protein Storage and Lytic Vacuoles. Plant Physiology. 145 (4):1383-1394.

Ortiz, L., Maldonado, H., Parra, P. y Graziani, L. 2006. Caracterización electroforética de las globulinas del grano fermentado de tres tipos de cacao. Interciencia. 31(006):441-445.

Osborne, T. 1924. The Vegetable Proteins. Longmans, Green and Co, London, p125. 
Park, M., Kim, S., Vitale, A. y Hwang, I. 2004. Identification of the Protein Storage Vacuole and Protein Targeting to the Vacuole in Leaf Cells of Three Plant Species. Plant Physiology. 134 (2):625639.

Peralta, M. E. 2004. Caracterización bioquimica de las proteinas de la semillas de Jatropha Curcas L. Tesis Maestro en ciencias, Instituto Politécnico Nacional, Yautepec Morelos.

Pereira, M., Rodrigues, I., Grossi-de-Sa, M. F. y Xavier-Filho, J. 2000. Do Legume Storage Proteins Play a Role in Defending Seeds against Bruchids?. Plant Physiology. 124 (2):515-522.

\section{Peumans, W. J., Proost, P., Swennen, R.L. y} Van Damme, J.M. 2002. The Abundant Class III Chitinase Homolog in Young Developing Banana Fruits Behaves as a Transient Vegetative Storage Protein and Most Probably Serves as an Important Supply of Amino Acids for the Synthesis of Ripening-Associated Proteins. Plant Physiology. 130 (2):1063-1072.

Ramos, O.J. 2009. Detección de péptidos de lupino similares a lunasina de soya. Tesis Maestro en Ciencias. Instituto Politécnico Nacional, Yautepec Morelos.

Rocha, G. F., Fernández, G. y Parisi, M.G. 2010. Estudios de Caracterización Cinética y Fisicoquímica de una Proteinasa Aspártica Aislada de Frutos Maduros de Salpichroa origanifolia. Información Tecnológica. 21 (2):21-28.
Rolletschek, H., Hosein, F., Miranda, M., Heim, U., Gotz, K. P., Schlereth, A., Borisjuk, L., Saalbach, I., Wobus, U. y Weber, H. 2005. Ectopic Expression of an Amino Acid Transporter (VfAAP1) in Seeds of Vicia narbonensis and Pea Increases Storage Proteins. Plant Physiology. 137:1236-1249.

Sabelli, P. A. y Larkins, B.A. 2009. The Development of Endosperm in Grasses. Plant Physiology. 149 (1):14-26.

Sales MP, Macedo MLR, Xavier-Filho J. 1992. Digestibility of cowpea (Vigna Unguiculata) vicilins by pepsin, papain and bruchid midgut proteinases. Comparative Biochemistry and Physiology - Part B. 103 (4):945-950.

Scott, N. 2008. Domain duplication, Darwinian selection and the origins of the seed storage globulins. Thesis Master of Science, Brigham Young University. Provo Utah.

Thompson, R., Burstin, J. y Gallardo, K. 2009. Post-Genomics Studies of Developmental Processes in Legume Seeds. Plant Physiology. 151 (3):1023-1029.

Torres, E., Gonzalez-Melendi, P., Stoger, E., Shaw, P., Twyman, R.M., Nicholson, L., Vaquero, C., Fischer, R., Christou, P. y Perrin, Y. 2001. Native and Artificial Reticuloplasmins Co-Accumulate in Distinct Domains of the Endoplasmic Reticulum and in Post-Endoplasmic Reticulum Compartments. Plant Physiology. 127 (3):1212-1223. 
Wieser, H. 2007. Chemistry of Gluten proteins. Food Microbiology. 24 (2): 115-119.

Wu, Y. y Messing, J. 2010. RNA InterferenceMediated Change in Protein Body Morphology and Seed Opacity through Loss of Different Zein Proteins. Plant Physiology. 153 (1):337-347.

Yamakawa, H., Hirose, T., Kuroda, M. y Yamaguchi, T. 2007. Comprehensive Expression Profiling of Rice Grain Filling-Related Genes under High Temperature Using DNA Microarray. Plant Physiology. 144 (1):258-277.

Zerené, M., Granger, D., Prehn, D., y Hinrichsen, P. 2000. Secuencias de microsatélites asociadas a genes de proteínas de reserva en variedades chilenas de trigo harinero: descripción y posible uso como marcadores de calidad panadera. Agricultura Técnica. $60(1): 14-31$.
Zhu, B. y Coleman, G. 2001. PhytochromeMediated Photoperiod Perception, Shoot Growth, Glutamine, Calcium, and Protein Phosphorylation Influence the Activity of the Poplar Bark Storage Protein Gene Promoter (bspA).Plant Physiology. 126 (1):342-351.

Zhu-Salzman, K., Luthe, D.S. y Felton, G. W. 2008. Arthropod-Inducible Proteins: Broad Spectrum Defenses against Multiple Herbivores. Plant Physiology. 146 (3):852-858. 